\title{
The self prefers itself? Self-referential versus parental standards in face attractiveness
}

Preference for phenotypic similarity in assortative mating may be influenced by either a preference for self-similarity or parent-similarity. The aim of the current study was to assess whether people's preference in face attractiveness is influenced by resemblance to the opposite sex parent's face (parental phenotype) or their own face (self-based phenotype or "self-imprinting"). We used computerized image manipulations of facial photographs of participants, their mothers and fathers. The original photographs were combined with $78 \%$ of the participants' opposite sex prototype face (i.e. male and female prototypes made from equal contributions of a hundred faces), creating morphs where the contribution from the familiar faces went unnoticed. Female and male participants ranked these images together with the opposite-sex prototype different familiar morphs. Each participant did the same for

the morphs generated with other same-sex participants' faces and of their parents. We found that the female participants preferred the self-based morphs to the prototype faces. Male participants showed a general tendency towards self-referential standard. Parental face morphs were ranked low in attractiveness, which may be accounted for by the age difference of the faces blended into the self-based versus parental face morphs, since we used presenttime photographs of both the participants and their parents. 


\author{
Unni Sulutvedt*, and Bruno Laeng \\ Department of Psychology, University of Oslo, Norway
}

2

$3 *$ Corresponding author. Unni Sulutvedt

4 E-mail address: unni.sulutvedt@psykologi.uio.no tlf 22845143, address Postboks 1094

5 Blindern0317 OSLO 
7 According to current evolutionary thinking, a recognition process based on phenotype

8 matching to specific individuals during early childhood provide the basis for whom will be

9 considered a potential sexual mate later in life. P. Bateson (1988, p. 265) postulated an "optimal

10 outbreeding" mechanism according to which "sexual imprinting sets the standard (or standards)

11 of what immediate kin look like and the animals subsequently prefer to mate with an individual

12 who looks slightly different." He also surmised that sexual imprinting exists in humans and that

13 self-stimulation with own phenotype (e.g., self's odor for some animals) may get sexually

14 imprinted. Indeed, several researchers have used the term sexual or familial "imprinting" during

15 childhood to describe an early learning process, often not in a strict Lorenzian sense (Lorenz,

16 1965) but as an "imprinting-like" type of mechanisms (e.g., Little et al., 2003) where early

17 experiences may have a primacy over later ones so that exposure to individuals that happen to be

18 in closest proximity during childhood (typically, close kin) are most likely to provide "templates"

19 for later mate choice (see also Lieberman, Tooby, \& Cosmides, 2007). Such a kin recognition

20 process is also at the foundation for seeking a balance between incest avoidance (cf. Shepher,

21 1971) and an opposite tendency to seek family resemblances.

22 In addition, D. Symons (1995) observed that, in current human environments, mirrors are

23 ubiquitous and they may affect attractiveness perception (particularly of same-sex individuals) in

24 evolutionarily unprecedented ways, and may even be responsible for some positive assortative

25 mating (Symons (1995; p. 108). However, he also stressed the possibility that already during the

26 course of human evolutionary history our ancestors could see their reflections in still water.

27 Hence, the historically recent spread of use of mirrors could have boosted the effects of an

28 already selected "self-imprinting" mechanism and humans did not need to wait for the

29 appearance of mirrors to get knowledge of self-appearance and be influenced by it. In fact, still 
30 water is highly reflective (consider the myth, at least 2,000 years old -of Narcissus falling in love

31 with his image in a pond) and reflective surfaces like still water have been present since the

32 beginning of evolutionary time. Thus, the potential for self-imprinting clearly predates the mass

33 production of mirrors, as well as that of portraits, homemade photos (e.g., "selfies") and movies.

34 Remarkably, people tend to marry individuals who are similar to themselves. This

35 phenomenon has been widely documented within Western societies (e.g., Alvarez \& Jaffe, 2004;

36 Bereczkei et al., 2002; Zajonc et al., 1987), where individuals tend to pair and wed willingly and

37 not that commonly in pre-arranged marriages. Some of these studies showed that when

38 participants were asked to pair pictures of unknown individuals of both sexes (Zajonc et al.,

39 1987), photos of actual partners were paired above chance. Moreover, Alvarez and Jaffe (2004)

40 found no difference between the matching of the ones most likely to be siblings and the ones

41 most likely to be married, which indicates the existence of a high degree of similarity between

42 partners. Finally, self-perception appears to modulate mate preference (Buston \& Emlen, 2003),

43 which is consistent with the hypothesis that human's criterion for beauty is rooted on an image of

44 self. These findings support the existence of a detection mechanism of similarity to the self that

45 influences attraction to others' faces.

46 Regarding mate choices, "imprinting" to the father's face has been shown to be relevant

47 for the daughter's facial preference (e.g., Wilson \& Barrett, 1987; Bereczkei et al., 2002; Little et

48 al., 2003; Watkins et al. 2012; Wiszewska et al., 2007). For example, females found facial stimuli

49 that resembled their father more attractive if they had a good relationship with their father during

50 childhood (e.g., Wiszewska et al., 2007). However, this imprinting-like process does not exclude

51 that also the self's face may have an impact on the formation of the kin template. Also, the child's

52 attachment to the mother figure and early exposure to the mother's face is essential in the social

53 development of humans (Bowlby, 1969; Belsky et al., 1991) and this could also influence later

54 affiliative choices. One possibility, which will be specifically explored in the present study, is that 
55 experiences of faces in close proximity during childhood could influence, at a later stage in life,

56 adults towards a "parental/kin standard" of attractiveness, featuring the facial characteristics of

57 self's parents. In addition, self-referential standards could become established over a lifetime

58 exposure with the self's own face and in fact reinforce kin-based preferences.

59 It is likely that several early "face templates" are shaped by exposure to faces throughout

60 childhood which leave a lasting impression on an individual's face processing mechanisms

61 (Perrett et al., 2002) and in turn influence mate choices in adulthood. Studies on facial

62 attractiveness are abundant and they have revealed that both the symmetry and averageness of a

63 face are crucial for attractiveness. However, if these were the sole perceptual factors affecting

64 people's sense of facial beauty, then most people will be most attracted to the average face (e.g. a

65 prototype; Halberstadt \& Rhodes, 2000).

66 A crucial assumption for the present study is that any deviation from the preference for

67 the prototype would support the idea that there exist important individual differences in the sense

68 of face aesthetics. Also, if facial preference is reduced to just a "mere exposure" phenomenon

69 (Hill, 1978; Moreland \& Zajonc, 1982), where highly familiar faces are regarded as more

70 likeable and attractive, then faces resembling any of the family faces (e.g., mother, father, as well

71 as self) should be found to be equally attractive and possibly preferred to the opposite-sex

72 prototypes. To our knowledge, attempts to separate a parental criterion from a self-referential

73 have never been tested by requesting the same group of participants to compare simultaneously

74 faces similar to themselves and their parents.

\section{Present study}

76 At the basis of the present research is evidence that lovers - when given the opportunity -

77 would prefer their partners to resemble themselves (Laeng, Vermeer, \& Sulutvedt, 2013). 
78 Specifically, a $22 \%$ self-based morph with the partner's face was preferred over the morph of the

79 partner's face with its same-sex's prototype. Thus, when given the opportunity, partners will

80 make aesthetic choices towards increased resemblance to self, either for the whole face or some

81 distinctive elements (e.g., the eyes' color; Laeng, Mathisen \& Johnsen, 2007). Nevertheless, it

82 remains unclear whether these findings reflect a self-referential mechanism or a parental

83 mechanism or a combination of the two. Thus, the present study attempted to tease apart the

84 contribution of familial imprinting to phenotype matching to self. To our knowledge, this is the

85 first time that the latter effects have been studied with graphic manipulation methods based on the

86 face images of the participants' parents.

87 Since the learning process of kin detection and imprinting may influence both sexual and

88 non-sexual preferences (e.g., trust or friendship), the effects of family resemblance may be better

89 captured by asking participants to rank images according to their "attractiveness", without

90 explicitly mentioning sexual attractiveness. Thus, we used computerized image manipulations,

91 morphs, of facial photographs of self, and self's biological mother and father in order to assess

92 this dilemma. That is, stimuli were made by a weighted average of every pixel in the two images,

93 so that all aspects of the faces (shape and pigment) were moved towards an intermediate

94 representation which was to all effect a novel face stimulus. We used the opposite-sex prototype

95 face (of the participant's age cohort) as the base image into which the same small amount of

96 information (22\%) of self, father, and mother were morphed. All images were presented

97 simultaneously as high-quality color prints and participants were asked to rank them for their

98 attractiveness. In addition, the same images from another subject's protocol were presented for

99 comparisons between Family and Other. The opposite-sex prototype face (i.e. the morphed

100 average of 100 people of the participants' age-cohort) was also presented, so as to provide a

101 baseline for comparing increase or decreases in the sense of beauty due to the other image

102 manipulations. 
104 use of "objective criteria of awareness" based on forced-choice tasks and signal detection

105 analysis (Merikle, Smilek \& Eastwood, 2001), to be perceived below consciousness, as opposed

106 to morphs with larger contributions, e.g. $33 \%$ (Laeng, Vermeer, \& Sulutvedt, 2013). Moreover,

107 Laeng, Vermeer, \& Sulutvedt (2013) found that attractiveness judgments on self-morphs

108 combined with attractive strangers peaked at $22 \%$, relative to $11 \%$ or $33 \%$ morphs. This may

109 indicate that $22 \%$ approximates the optimal amount of likeness in order to prevent avoidance

110 mechanisms of primary incest. As seen in a pilot study, this $22 \%$ peak effect was not observed if

111 the strangers face was previously rated as unattractive, in which case other evolutionary

112 "constraints" may dominate - e.g. the variations in asymmetry of individual faces (cf. Rhodes,

113 2006; Miller \& Todd, 1998). Therefore, when morphing, we used the opposite-sex prototype

114 faces, in order to achieve a face of optimal averageness and symmetry.

115 We need to stress that we are not suggesting that average faces are optimally attractive but

116 only that average facial configurations are more attractive than most faces (Rhodes 2006). The

117 logic behind our study is simply based on the well-documented fact that the symmetrical

118 averaged face obtained when morphing multiple faces typically score very high in attractiveness

119 and when adding to a prototype a sizable proportion of a randomly chosen face, this does not

120 cause an increase of attractiveness but typically reduces it a bit. Based on the above evidence, we

121 hypothesize that adding to a prototype a $22 \%$ of oneself or kin should result in no gain in

122 attractiveness unless self's appearance or kin's are actually "liked."

123 The predictions are quite straightforward: If the preference for the phenotype is strongly

124 based on a self-referential process the self-morph should be preferred to all other morphs. In

125 contrast, the self-morph should be ranked as less attractive than the morphs based on kin's faces

126 if parental imprinting plays an important role. Since our participants were heterosexual, we also

127 predicted that the maternal morph should be preferred to the paternal by male participants while 
128 the reverse should happen for the female participants. Finally, if facial preference is caused by a

129 "mere exposure" phenomenon, all the morphs based on the familiar faces (e.g., mother, father, as

130 well as self) should be found to be equally attractive.

131 However, we need to point out from the outset a caveat of the present experiment: We

132 were able to use only 'present-time' images of the participant's parents, which may not be ideal

133 for studying the influence of parental effects, since parents do not look exactly the same today as

134 they did when a parental standard could have been established. Nevertheless, the present study is

135 an initial and direct test of the parental-template hypothesis. Since a few previous studies have

136 also shown that individuals' preferences in attractiveness may be influenced by attachment

137 experiences in adults' upbringing (e.g., Wiszewska et al., 2007; Nojo, Tamura \& Ihara, 2012), we

138 also used the short form of the EMBU scale (Arriendell, 1999) to assess positive versus negative

139 attachment to the mother and the father figure.

Materials and Methods

141 Participants The study included a total of 36 heterosexual participants (18 females)

142 between the age of 18 and 33 with normal or corrected to normal vision (mean age $=25.50 ; S D=$

143 4.24). The participants were recruited in the Oslo area, either at seminars at the Department of

144 Psychology or by word of mouth.

145 Psychological research in Norway is subject to ethical review by the regional medical

146 research board only if the research involves patients, children or animals and involves drugs,

147 genetic samples or invasive techniques. Since none of these conditions applied to the present

148 study, the academic institution demanded only that the project comply with Declaration of

149 Helsinki guidelines and that informed consent be obtained from the participants. We obtained

150 written consent from all participants, and participants were free to withdraw from the project. 
152 all the 36 participants and their biological mothers and fathers. A total of 108 photographs, using

153 a Panasonic Lumix DMC digital camera, were collected. When parents lived far away, high

154 quality digital photographs were sent by e-mail. The photographs were taken from a distance of 1

155 meter, and participants and their parents were asked to display a neutral, emotionless facial

156 expression. Facial hair was removed and deep creases, folds, and lines of the skin were retouched

157 using Adobe Photoshop ${ }^{\odot}$ to reduce age effects. We chose to use pictures of parents from present

158 time, after failing to collect pictures of parents from the time their children were young. The old

159 pictures were of too poor quality and not sufficiently standardized (e.g. some showed smiling

160 faces, eye-glasses, different poses, etc.), so that morphing these old pictures with the high quality

161 prototypes would not yield satisfactory images. Hence, we opted to using current photos taken

162 with the same digital camera and in standard pose, and with neutral expressions.

163 Using image-morphing software (Morpheus Photo Morpher ${ }^{\odot}$ ), $22 \%$ of all the original

164 photographs were blended in with the opposite sex prototype face of the participant's age cohort

165 (made from 100 faces) to create self-referential, paternal, and maternal morphs (see Fig. 1). On

166 all images, 71 points were placed on different features of the faces before morphing. As in Lie,

167 Rhodes and Simmons (2008) these color morphs $(239 \times 316 \mathrm{~cm})$ were digitally fitted with an

168 oval black mask (not shown in the Figure) to reduce any effects of clothing and hairstyle, leaving

169 only the face and minimal hair visible.

170 The s-EMBU retrospective attachment test (Arrindell et al., 1999; 2001) was used to

171 control for perceived parental attachment in childhood. The s-EMBU is a 23-item inventory with

172 4-point Likert type scales, to be answered separately for mother and father. This test consists of

173 three scales: Emotional Warmth, Rejection, and (Over) Protection each of which comprises eight

174 items. Following Gyuris, Járai, Bereczkei (2010) only Emotional Warmth and Rejection was used

175 to assess perceived positive and negative emotions towards parents during upbringing. 
177 Procedure Each participant was matched by age to another participant of the same sex so

178 as to obtain a set of morphs for the "Other" condition. Four morphs of were presented side by

179 side for each separate sessions for "Family" or "Other" conditions. The participants were asked to 180 rank them from the most attractive (i.e., $1^{\text {st }}$ place) to the least (i.e., $3^{\text {rd }}$ place). The order of the 181 images was random within each block. All the stimulus images were presented centered on the 182 computer screen with a resolution of 1024 x 768 pixels. The software "Experiment Center" by 183 SensoMotoric Instruments ${ }^{\circledR}$ (SMI, Teltow, Germany) was used to present the stimuli. Participants were tested individually and were seated in front of a computer screen at a

185 distance of $60 \mathrm{~cm}$. A blank screen was presented for $500 \mathrm{~ms}$ followed by a fixation cross 186 presented for $1000 \mathrm{~ms}$ and then the image-set was viewed as long as it took to make a decision, 187 and the participants pressed space on the keyboard to move on to the next image-set. The 188 experimenter manually recorded the attractiveness responses (hence we did not analyze response 189 times), and the experiment lasted approximately 30 minutes, followed by the short questionnaire.

190 After the experiment all the participants were debriefed and asked if they had recognized any of 191 the faces. Only two participants thought they might have recognized their opposite-sex parent, 192 and said they had consequently ranked these morphs in $3^{\text {rd }}$ place. However, removing these 193 participants from the analyses did not affect the overall results and, therefore, we present below 194 results from all participants' responses.

\section{Results}

196 All data were analyzed using StatView ${ }^{\circledR}$ statistical package. t-tests for independent 197 samples were conducted on the s-EMBU to compare differences between sexes in perceived 
198 parental behavior. There were no significant differences in the ratings between females and males

199 in any of the elements in the s-EMBU; mother rejection $(p=.68)$, father rejection $(p=.32)$,

200 mother emotional warmth $(p=.57)$, and father emotional warmth $(p=.40)$. All participants were

201 high on parental emotional warmth and low on parental rejection, thus, the s-EMBU was not used 202 in further analyses.

203 Descriptive statistics were calculated for each participant, obtaining mean attractiveness

204 ranks for each combination of the variables (Tables 1 and 2). Rankings from female and male 205 participants were analyzed separately, since the parental hypothesis predicts opposing differences 206 in attractiveness between parental sexes. The attractiveness rankings were analyzed using the 207 Friedman's Rank Test and pair-wise comparisons were carried out with the Paired Sign Test. 208 The analysis of the female participants in the Family group showed significant difference 209 in ranking of morphs: $\chi^{2}=17.23, \mathrm{df}=3, p<.0005$ (see Table 1 , top). The self-morph was ranked 210 first and the male prototype was ranked second place, these differed significantly from each other 211 according to a Paired Sign Test $(p<.03)$, confirming the presence of a self-referential preference 212 over and above a preference for average and symmetric faces of the opposite sex. The self-morph 213 also differed significantly from both the mother $(p<.002)$ and father $(p<.006)$ morphs. The

214 prototype was preferred significantly to the mother morph $(p=.049)$. Interestingly, comparing

215 the male prototype and the father's morph showed no significant difference between their ranks

$216(\mathrm{p}=.21)$, which shows that the parental face did not invariably resulted in an unattractive face 217 morph. 
221 top). However, the difference between the Other morph (i.e., the morph replacing the self-morph

222 of the above analyses, Table 2$)$ and the male prototype failed to be significant $(p=.212)$, which

223 confirms that only when the morph contains a bit of self-resemblance is preferred over the

224 prototype. The prototype was significantly preferred to both the Other's mother morph ( $p=.03)$

225 and the Other's father morph $(p=.001)$. Finally, Other was preferred to both Other's mother

226 morph $(p=.005)$ and the Other's father morph $(p=.052)$. There was no difference in the ranks of

227 the Other's mother morph versus the Other's father morph $(p=.091)$.

228 Analysis of male participants in the Family group revealed the presence of a a significant

229 difference among ranks, $\chi 2=8,20, \mathrm{df}=3, p=.04$ (see Table 1, bottom). This was entirely

230 accounted, according to the Paired Sign Tests, by a significant difference for the morph ranked

231 first versus the one ranked last, i.e. the female prototype over the father morph $(p=.041)$. When

232 the same male participants judged morphs in the Other set, they showed significant differences in 233 their ranking of attractiveness, $\chi 2=19.95, \mathrm{df}=3, p<.0001$ (see Table 2, bottom). They clearly

234 preferred the female prototype over the Other morph $(p=.0013)$ as well as the Other's father $(p=$ $235.0001)$ or mother morphs $(p=.01)$. Moreover, the Other morph was significantly preferred to the 236 Other's father morph $(p=.0001)$ as well as to the Other's mother morph $(p=.01)$.

Discussion

The present results are consistent with the hypothesis that people possess a self-referential

239 standard of face attractiveness, since self-based morphs were preferred to the prototype morphs,

240 especially by the female participants. They are also in line with several previous findings of

241 "narcissistic" preferences for faces (e.g., Alvarez \& Jaffe, 2004; Bereczkei et al., 2002; Zajonc et

242 al., 1987, Laeng, Vermeer \& Sulutvedt, 2013). Interestingly, a previous study with morphs

243 (Laeng, Vermeer \& Sulutvedt, 2013) also revealed stronger preferences for self-morphs in

244 females than in males. It is possible that these effects may be caused by a greater tolerance for 
245 same-sex blends (i.e., feminization) with female participants than for the males (i.e.,

246 masculinization). Another possibility is that females are more exposed on average than males to

247 the self's phenotype by use of mirrors. In the present study, the male participants' choices were

248 also consistent with a self-referential standard, since for male participants the female prototype

249 did not differ significantly in attractiveness from the self-morph.

250 However, we failed to show evidence in favor of the parental template hypothesis or

251 family imprinting hypothesis, because the self-morph was preferred over the maternal and

252 paternal morphs and the opposite-sex prototype was preferred over both parental morphs. In

253 addition, the Other morphs were ranked above their parents' morphs. When taken together these

254 results suggest that there was an effect of the age of the face morphed into the prototype, where

255 the older ages of parents to both self's and other's reduced the attractiveness of all parental

256 morphs. Clearly, a caveat of the present experiment is that it used 'present-time' images of

257 parents which may have counter-acted the influence of possible parental effects, since parents do

258 not look exactly the same today as they did when a possible parental standard could have been

259 "imprinted". Although we digitally retouched skin creases, folds, and lines to reduce the cues of

260 age, the wide age difference may still create confounds in the images. If a parents' template is

261 established during the first years of life, individuals might actually be mostly attracted to faces

262 resembling what the parent looked like at the time self was a child.

263 However, it is interesting to note that while the females significantly preferred the male

264 prototype to both Other's mother and father morphs, this difference disappeared when the male

265 prototype was compared to the self's father morph. This suggests that family resemblance to the

266 opposite-sex parent may at least mitigate the negative "age effect" on females' preference. A few

267 previous studies have found the presence of facial similarities between face of spouse and the

268 parent of the opposite sex (Little et al., 200; Marcinkowska \& Rantala, 2012; Wilson \& Barrett,

269 1987; Wiszewska et al., 2007). One study on facial similarity between spouses and their parent 
270 (Nojo, Tamura \& Ihara, 2012) used images of parents from when the participants were children,

271 and found no clear implications of the similarity between the couples and their mother/father-in-

272 law. Thus, the present results only allow us to draw tentative conclusions about parental versus

273 self-referential tendencies in face attractiveness, since it is difficult to disentangle the effects due

274 to the age of the face morphed into the prototype from that of its family status and the present

275 results are largely consistent with younger faces being preferred to older ones. .

276 In addition, we found no significant differences in ratings of perceived Emotional Warmth

277 or Rejection from fathers or mothers during upbringing. All the participants had quite similar

278 mean scores, as both parents were rated rather high on Emotional Warmth and low on Rejection.

279 Despite the participants' seemingly good relationship to their parents, the self-resembling faces

280 were chosen over the parents faces, suggesting that positive feelings towards parents do not

281 indicate a greater parental tendency in face attraction. Wiszewska et al. (2007) compared facial

282 proportions of fathers' faces to the proportions of the facial stimuli chosen by females as the most

283 attractive. They found that there was no concordance overall between fathers face and chosen

284 stimuli, but if the women rated their fathers highly the proportions of the attractive stimuli was

285 more similar to the fathers' faces. They did not, however, test for similarity between the

286 daughters' and the fathers' faces. There is a possibility that the females that rated their fathers

287 most positively also were more facially like their fathers, so a self-referential preference may be a

288 contributing factor. Other studies have found evidence that daughters of older men tend to choose

289 older husbands (Wilson, \& Barrett, 1987), and prefer age cues in male faces compared to cues of

290 youth (Perrett et al., 2002). This effect may be the result of a parental tendency, but it could also

291 simply be due to familiarity with older people. In addition, the above studies did not investigate

292 whether the chosen husbands and stimuli had any facial resemblance with the females' fathers or

293 the self. 
Although the presence of mirrors, photos, films, and drawings in modern times may have

295 considerably boosted, compared to the evolutionary past, sexual self-imprinting in humans, the

296 empirical evidence in humans for sexual imprinting (either positive or negative) remains weak

297 (e.g. Marcinkowska \& Rantala 2012; Rantala \& Marcinkowska, 2011). Moreover, it remains

298 unclear if self-imprinting should be considered an adaptive strategy or it could have become

299 maladaptive by promoting an excessive tendency towards inbreeding. However, there is

300 empirical evidence suggesting that the 'like mate with like' strategy (whether this may based on

301 kin's or self's phenotypes) can confer adaptive value. Remarkably, it has been shown in a study

302 on the whole population of Iceland that a moderate degree of genetic similarity increases

303 reproductive success and genetic compatibility in humans; specifically, there was a positive

304 association between kinship and fertility, so that Icelandic couples that were mildly related (i.e.,

305 third or fourth cousins) had the greatest reproductive success and the highest number of children

306 who further reproduced (Helgason et al. 2008). Moreover, self-resemblance in both physical and

307 psychological phenotypes may indicate suitability to one's environment and, in humans, could

308 promote the partners' successful cooperation, relevant for the survival of the offspring (Godoy et

309 al. 2008). There are also examples of use in humans of physical cues based on 'kin' resemblance

310 that are strategical in evolutionary terms, for example for detecting cuckoldry (for example in the

311 face, see Bovet et al., 2012; Laeng et al. 2007; Platek \& Thomson 2007);

312 The well-documented phenotypic similarity among partners in many human societies may

313 thus reflect inclusive fitness mechanisms, where there can be increased gene duplication without

314 an increase in reproductive investment and a reduced cost of altruism (Epstein \& Guttman 1984;

315 Thiessen \& Gregg, 1980). Given that phenotypic facial characteristics are known to be highly

316 heritable in humans (Baydas et al., 2007; Weinberg et al., 2013), faces may be one of the best

317 visual clues to genetic similarity (Kazem, \& Widdig, 2013; Holmes, 2004, Bovet et al., 2012).

318 Indeed, for both sexes, ratings of facial attractiveness have been found to be a better predictor of 
319 general physical attractiveness than ratings on body images (Currie \& Little, 2009; Peters,

320 Rhodes, \& Simmons, 2007). Whether people could see themselves having a relationship with a

321 stranger can be predicted by the stranger's face attractiveness (Currie \& Little, 2009), which

322 imply that face attractiveness is an important feature in human mate choice decisions and that

323 faces may provide relevant signals of heritable quality (Tregenza \& Wedell, 2000).

324 To conclude, although a universal preference for the human prototype is well-documented

325 (e.g., Rhodes, 2006), such a preference could derive from general processing mechanisms or from

326 self's exposure to other non-related individuals. Thus, a key difference from parental or self-

327 referential "imprinting" and general prototype learning is that the latter may be based on self's

328 exposure to non-related and mostly unknown individuals over a lifetime; whereas the former

329 would be linked to early exposure to figures of attachment and self. Thus, mate choice could be

330 the result of a delicate balance between opposing tendencies: inbreeding versus outbreeding;

331 universal "ideals" of beauty versus highly idiosyncratic preferences based on one's own

332 appearance. The interplay between choices based on universal standards of beauty (i.e. symmetry

333 and averageness versus the personal self-based ones) is well expressed in an aphorism by poet

334 W.H. Auden (1962): "Narcissus does not fall in love with his reflection because it is beautiful, but 335 because it is his." 
337 Alvarez L, Jaffe K. 2004. Narcissism guides mate selection: Humans mate assortatively, as revealed by facial resemblance, following an algorithm of "self seeking like". Evolutionary Psychology 2: 177-194.

Arrindell WA, Sanavio E, Aguilar G, Siva C, Hatzichristou C, Eisemann M, Recinos LA, Gaszner P, Peter M, Battagliese G, Kállai J, van der Ende J .1999. The development of the short form of the EMBU: Its appraisal with students in Greece, Guatemala, Hungary and Italy. Personality and Individual Differences 27: 613-628.

\section{Arrindell WA, Richter J, Eisemann M, Gärling T, Rydén O, Hansson SB, Kasielke E,} Frindte W, Gillholm R, Gustafsson M. 2001. The short-EMBU in EastGermany and Sweden: A cross-national factorial validity extension. Scandinavian Journal of Psychology 42: 157-160.

348 Auden WH (1962). "Hic et Ille," pt. 3, sct. A, in The Dyer's Hand. Random House (1990 $349 \quad$ Edition).

350 Bateson P (1978). Sexual imprinting and optimal outbreeding. Nature 273: 659-60.

351 Bateson P. 1983. Optimal outbreeding. In: Bateson P (ed) Mate choice. Cambridge University Press, pp 257-277.

353 Belsky J, Steinberg L, Draper P. 1991. Childhood experience, interpersonal development, and 354 355 reproductive strategy: An evolutionary theory of socialization. Child Development 62: 647-670.

Bereczkei T, Gyuris P, Koves P, Bernath L. 2002. Homogamy, genetic similarity, and 358 imprinting; parental influence on mate choice preferences. Personality and Individual 
359 Bovet, J, Barthes, J, Durand, V, Raymond, M, and Alvergne, A. 2012. Men's preference for women's facial features: Testing homogamy and the paternity uncertainty hypothesis. PloSOne 7: e49791 DOI: 10.1371/journal.pone.0049791.

362 Bowlby J. 1969. Attachment and loss, Vol. 1: Attachment. New York: Basic Books.

363 Buston PM, Emlen ST. 2003. Cognitive processes underlying human mate choice: The relationship between self-perception and mate preference in Western society. Proceedings of the National Academy of Sciences 100: 8805-8810 doi:10.1073/pnas.1533220100 .

366 Currie TE, Little AC. 2009. The relative importance of the face and body in judgments of human physical attractiveness. Evolution of Human Behavior 30: 409-416 doi:10.1016/j.evolhumbehav.2009.06.005.

Epstein E, Guttman R. 1984. Mate selection in man: evidence, theory, and outcome. Social Biology 31: 243-78.

Godoy R, Eisenberg DTA, Reyes-Garcı'a V, Huancad T, Leonard WR, et al. 2008. Assortative mating and offspring well-being: theory and empirical findings from a native Amazonian society in Bolivia. Evolution and Human Behavior 29: 201-210.

374 Gyuris P, Járai R, Bereczkei T. 2010. The effect of childhood experiences on mate choice in

375

376

377

378

379

380

381

382 personality traits: Homogamy and sexual imprinting. Personality and Individual Differences 49: 467-472 doi.org/10.1016/j.paid.2010.04.021.

Halberstadt J, Rhodes G. 2000. The attractiveness of nonface averages: Implications for an Evolutionary Explanation of the Attractiveness of Average Faces. Psychological Science 11: 285-289 doi: 10.1111/1467-9280.00257.

Helgason A, Pálsson S, Guðbjartsson DF, Kristjánsson P, Stefánsson K. 2008. An association between the kinship and fertility of human couples. Science 319: 813-816 doi: 10.1126/science. 1150232 
383 Hill WF. 1978. Effects of mere exposure on preferences in nonhuman mammals. Psychological $384 \quad$ Bulletin 85: 1177-1198.

385 Holmes WG. 2004. The early history of Hamiltonian-based research on kin recognition. Annales Zoologici Fennici 41: 691-711.

387 Laeng, B., Vermeer, O., \& Sulutvedt, U. 2013. Is beauty in the face of the beholder? PLoS ONE 388 8: e68395 doi:10.1371/journal.pone.0068395.

389 Lieberman D, Tooby J, Cosmides L. 2007. The architecture of human kin detection. Nature $390 \quad$ 445: 727-731 doi:10.1038/nature05510.

391 Little AC, Penton-Voak IS, Burt DM, Perrett DI. 2003. Investigating an imprinting-like 392 phenomenon in humans, partners and opposite-sex parents have similar hair and eye 393 colour. Evolution of Human Behavior 24: 43-51.

394 Lorenz, K. 1965. Evolution and modification of behaviour. University of Chicago Press, 395 Chicago.

396 Marcinkowska UM \& Rantala MJ. 2012. Sexual imprinting on facial traits of opposite-sex 397 parents in humans. Evolutionary Psychology 10: 621-630.

398 Miller GF, Todd PM. 1998. Mate choice turns cognitive. Trends in Cognitive Science 2: 190399198.

400 Nojo S, Tamura S, \& Ihara Y. 2012. Human homogamy in facial characteristics: Does a sexual401 imprinting-like mechanism play a role? Human Nature 23: 323-340.

402 Perrett D, Penton-Voak IS, Little AC, Tiddeman BP, Burt DM, Schmidt N, Oxley R, 403 Kinloch N, Barrett L. 2002. Facial attractiveness judgments reflect learning of parental 404 age characteristics. Proceedings of the Royal Society London B 269: 873-880 $405 \quad$ DOI:10.1098/rspb.2002.1971.

406 Peters M, Rhodes G, Simmons LW. 2007. Contributions of the face and body to overall 407 attractiveness. Animal Behavior 73: 937-942 doi:10.1016/j.anbehav.2006.07.012. 
408 Platek SM, Thomson JW. 2007. Facial resemblance exaggerates sex-specific jealousy-based 409 decisions. Evolutionary Psychology 5: 223-231.

410 Rantala MJ, Marcinkowska UM. 2011. The role of sexual imprinting and the Westermark effect in mate choice in humans. Behavioral Ecology and Sociobiology 65: 859-873.

412 Rhodes G. 2006. The evolutionary psychology of facial beauty. Annual Review of Psychology 57: 199-226 DOI:10.1146/annurev.psych.57.102904.190208.

414 Shepher, J. 1971. Mate selection among second generation kibbutz adolescents and adults: Incest avoidance and negative imprinting. Archives of Sexual Behavior, 1: 293-307.

Thiessen D, Gregg B. 1980. Human assortative mating and genetic equilibrium: An evolutionary perspective. Ethology and Sociobiology 1: 111-140.

Tregenza T, Wedell N. 2000. Genetic compatibility, mate choice and patterns of parentage: invited review. Molecular Ecology 9: 1013-27 DOI: 10.1046/j.1365-294x.2000.00964.x.

Watkins CD, DeBruine LM, Smith FG, Jones BC, Vukovic J, et al. 2012. Like father, like self: Emotional closeness to father predicts women's preferences for self-resemblance in opposite-sex faces. Evolution and Human Behavior 32: 70-75.

423 Weinberg SM, Parsons TE, Marazita ML, Ma-her BS. 2013. Heritability of face shape in twins: a pre-liminary study using 3D sterophotogrammerty and ge-ometric

425 morphometrics. Dentistry 3000 1:a004 doi: 10.5195/d3000.2013.14.

426 Wilson GD, Barrett PT. 1987. Parental characteristics and partner choice: Some evidence for 427 Oedipal imprinting. Journal of Biosocial Science 19: 157-161

428 Wiszewska A, Pawlowski B, Boothroyd LG. 2007. Father-daughter relationship as a moderator 429 of sexual imprinting: A facialmetric study. Evolution and Human Behavior 28: 248-252

430 DOI: $\underline{10.1016 / j . e v o l h u m b e h a v .2007 .02 .006 . ~}$

431 Zajonc R, Adelmann P, Murphy S, Niedenthal P. 1987. Convergence in the physical 432 appearance of spouses. Motivation and Emotion 11: 335-346. 


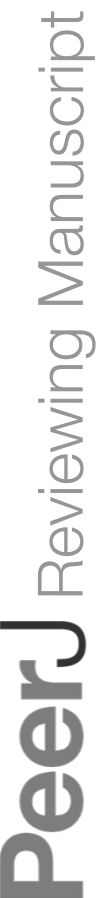

PeerJ reviewing PDF | (v2014:04:1991:2:0:NEW 22 Aug 2014) 


\section{Figure 1}

Examples of morphed image-set and original images

Top row: Examples of the morphed image-set based on the author: A) Self, B) Mother, and C) Father. Bottom row: Original images of the author D) Self, E) Mother, and F) Father.
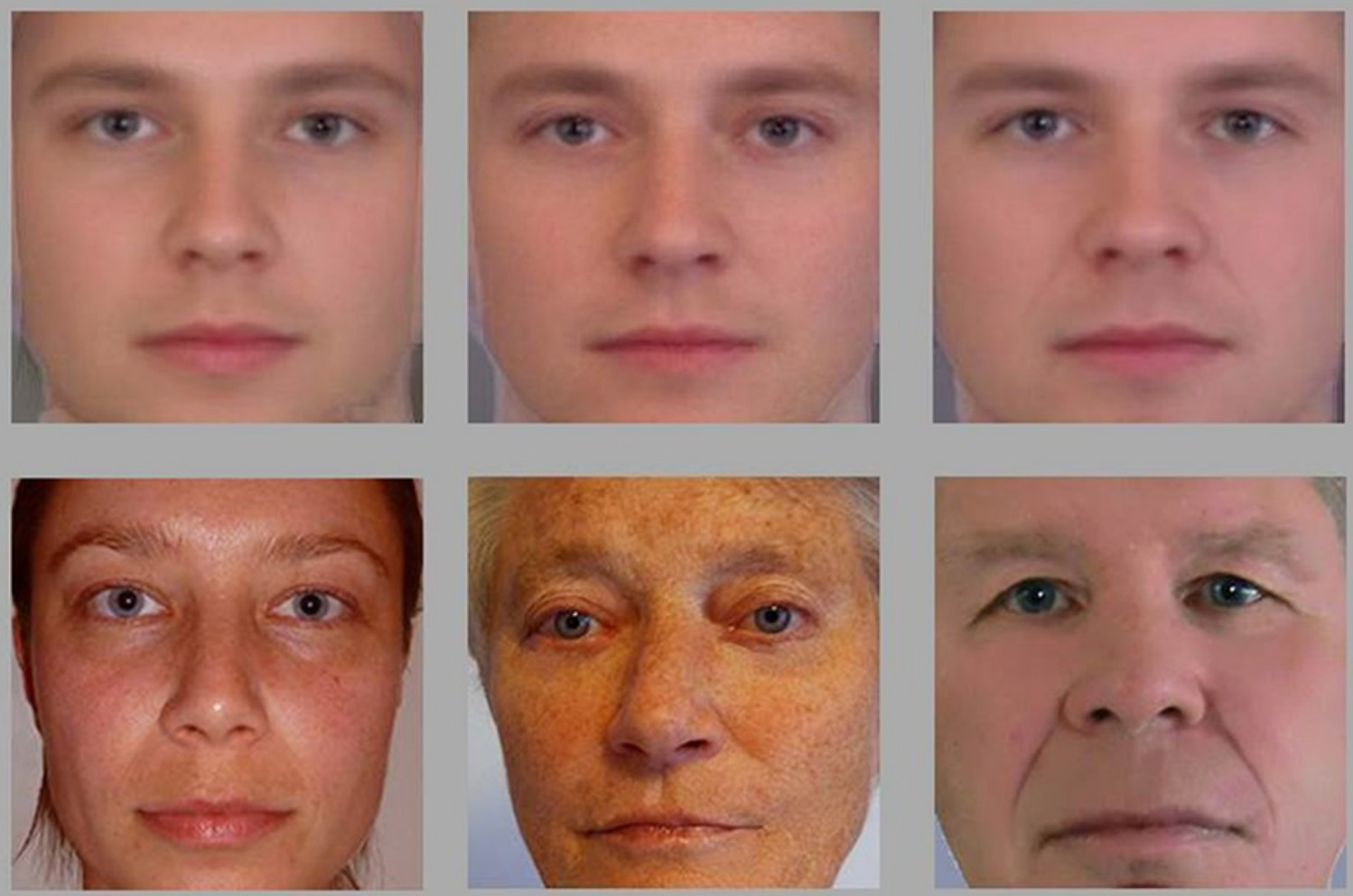


\section{Table 1 (on next page)}

Family morphs

$\stackrel{.}{*} \quad$ Mean ranks for Family morphs. 


\section{Family}

\begin{tabular}{lc}
\hline Female Participants & Mean rank \\
\hline Self morph & 1.53 \\
Male prototype & 2.36 \\
Self's Mother morph & 2.97 \\
Self's Father morph & 3.14 \\
& \\
& \\
& \\
\hline Male Participants & \\
\hline Female prototype & 1.89 \\
Self morph & 2.33 \\
Self's Mother morph & 2.72 \\
Self's Father morph & 3.06 \\
\hline
\end{tabular}




\section{Table 2 (on next page)}

Other morphs

Mean ranks for Other morphs (i.e., non-familiar faces). The 'Other' morphs were the same images labeled in Table 3 as 'Self' morphs. 


\section{Other}

\begin{tabular}{lc}
\hline Female Observers & Mean rank \\
\hline Other morph & 1.93 \\
Male prototype & 2.15 \\
Other's Mother morph & 2.84 \\
Other's Father morph & 3.08 \\
& \\
\hline Male Observers & \\
\hline Female prototype & Mean rank \\
Other morph & 1.50 \\
Other's Mother morph & 2.50 \\
Other's Father morph & 2.58 \\
\end{tabular}

